\title{
Aportaciones para la Gestión Integral de las Redes Camineras Rurales
}

\author{
Fermín RODRÍGUEZ GUTIÉRREZ \\ Departamento de Geografía y CeCodet. Universidad de Oviedo \\ farragut@uniovi.es
}

José Ángel FERNANDEZ PRIETO

CeCodet. Universidad de Oviedo

Recibido: 22 de septiembre de 2012

Enviado a evaluar: 22 de enero de 2013

Aceptado: 8 de julio de 2013

\section{RESUMEN}

El camino, entendido como infraestructura del medio rural, demanda, tanto por su importancia para las economías locales como por el potencial impacto que su construcción puede ocasionar en el paisaje, un marco normativo consensuado y operativo, de carácter territorial, que establezca procedimientos útiles en todo su proceso. Proceso que incluye desde el reconocimiento e inventario de la red caminera de determinado territorio hasta la señalización y mantenimiento, pasando por la toma de decisiones de actuación y la obra de la vía. Tal marco normativo no lo hay en España, lo que da lugar a descoordinación entre administraciones, población y sectores económicos, a actuaciones desafortunadas para el paisaje y el medio rural, y a gastos económicos superfluos. Se proponen principios, buenas prácticas de intervención y metodologías cuya finalidad es contribuir a fijar procedimientos válidos para la gestión de las redes camineras rurales.

Palabras clave: Camino rural, buenas prácticas, plan forestal, paisaje, integración, funcionalidad.

\section{Contributions for integrated management of rural road networks}

\begin{abstract}
The road, understood as an infrastructure in a rural environment, demands, for its importance for the local economy and its potential impact in the landscape, a consensual and operating legal framework, with a territorial character, establishing helpful procedures in all its process. This is a process that includes from recognizing and inventorying the roads of a territory, to signaling and maintenance, including the decision process and the road work. That kind of legal framework doesn't exist in Spain, resulting in incoordination between administrations, local population and economic sectors, in bad actions for landscape and rural environment, and in unnecessary economic costs. Here we propose principles, good intervening practices and methodologies whose purpose is to help establish valid procedures for rural roads management.
\end{abstract}

Key words: Rural road, good practices, forest plan, landscape, integration, functionality. 


\section{Contributions pour la gestion intégrée des réseaux de routes rurales}

\section{RÉSUMÉ}

La route es una infrastructure qui peut être dans les régions rurales. Besoin d'un cadre réglementaire consensuelle et d'exploitation, d'échelle territoriale, car il est très important pour l'economie locale et pour l'impact que sa construction peut conduire à des paysages. Le processus devrait comprendre la reconnaissance et l'inventaire des routes, le processus décisionnel, la construction de la route, signalisation et maintenance. Ce cadre n'existe pas en Espagne. Pour cette raison, il ya beaucop incoordination entre l'administracion territoriale, la population et les secteurs économiques, ouvres atteinte aux paysages et inútiles coûts économiques. Dans cet article, nous proposons príncipes, bonnes pratiques d'intervention et methodologies qui comportant la cible de établir procedures opérationnelles pour gérer les routes rurales.

Mots clés: Route rural, bonnes pratiques, plan d'aménagement forestier, paysage, intégration, fonctionnalité.

\section{CAMINOS QUE NO LLEVAN A NINGÚN LUGAR}

Durante uno de los numerosos reconocimientos territoriales que en 2011 los investigadores del CeCodet realizaron por los concejos rurales de Asturias, en el marco del proyecto Aprovechamiento del potencial de los caminos rurales de España ${ }^{l}$, se hizo evidente la necesidad de establecer un marco normativo común que ofreciera un hilo conductor para la intervención de los distintos agentes (instituciones, usuarios y sectores económicos) sobre las redes de caminos.

Numerosas jornadas de trabajo de campo, reuniones con todos los sectores implicados y el desarrollo de fichas de inventario y de un Sistema de Información Geográfica habían dado lugar a un complejo análisis de la red de caminos de los municipios estudiados. Los investigadores expusieron los resultados de su trabajo a la administración local, a la autonómica, a los técnicos y agentes de la guardería rural y a la población local en un intento de implicar a todas las partes interesadas en el proceso de toma de decisiones para el acondicionamiento de la red caminera de los municipios, que se realizaría siguiendo un catálogo de buenas prácticas redactado por CeCodet en $2010^{2}$.

En uno de los municipios se determina por acuerdo el camino sobre el que actuar, la administración contrata a una empresa de ingeniería para redactar el proyecto de obra que va a servir de proyecto-piloto y ésta comienza su trabajo, como elemento final de una larga y ancha cadena de eslabones perfectamente acuartelados.

\footnotetext{
${ }^{1}$ Las características de este proyecto y los resultados obtenidos en él se corresponden con el capítulo 3 de este artículo.

${ }^{2}$ Con título Recomendaciones para la intervención en vías de paisaje. De las propuestas contenidas en él se habla en el capítulo 2 de este artículo.
} 
Pero no era tan sólida la trabazón, pues en aún en el esbozo de lo que podría desembocar en un programa normalizado referido a la intervención y gestión de las redes de caminos rurales, la administración local introdujo, por su cuenta y riesgo, maquinaria en el camino de actuación-piloto, destrozando la vía preexistente y dibujando un nuevo trazado, que confluía y se separaba aleatoriamente de la traza original, incumpliendo la mayoría de buenas prácticas y principios en que se basaba el proyecto. El nuevo trazado abierto, ciertamente, sin premeditación pero si de manera alevosa, salvaba desniveles superiores al $20 \%$ en una ladera libre de vegetación, causando un alto impacto paisajístico, y la ausencia de firme y elementos de contención de laderas de la nueva obra multiplicaba los problemas de escorrentía, comprometiendo la funcionalidad y seguridad del improvisado nuevo camino.

Se trata de un suceso acaecido durante el proyecto que nos parece claro ejemplo de lo que no debe suceder en el tratamiento de las redes de caminos rurales de España. Hay un vacío legal cuando nos planteamos qué hacer con el camino; no entendido como una línea aislada que trazamos sobre un terreno carente de personalidad, sino como infraestructura del medio rural y del paisaje que durante siglos se ha configurado, resultado de la interacción entre los elementos geológicos, biológicos y antrópicos. Una infraestructura que debe garantizar la funcionalidad tradicional del medio donde se inserta y abrirse a nuevas oportunidades de desarrollo para contribuir a frenar la decadencia que afecta a gran parte del medio rural español.

No puede fiarse todo al espontaneismo voluntarista o al ojo del palista y al sentido común del capataz de obra. Lo que para el alcalde de un municipio puede resultar beneficioso a corto plazo, quizá tenga consecuencias negativas en la sostenibilidad del modelo o en las arcas municipales. Lo que para la explotación forestal puede ser interesante, puede serlo menos para el medio ambiente. O viceversa. El desafío es establecer y aplicar procedimientos válidos y consensuados, que en esta materia den solución a las necesidades del medio rural y respondan a principios de integración, funcionalidad y adaptación al paisaje.

Lo que sigue es la modesta aportación que durante dos años de trabajo el CeCodet de la Universidad de Oviedo, acompañado de otros, ha realizado en la búsqueda de un marco común.

\section{RECOMENDACIONES PARA LA INTERVENCIÓN EN VÍAS DE PAISAJE}

En el marco de este proyecto se redactó un catálogo de buenas prácticas para la construcción de caminos rurales. Para ello, se establecieron unos principios funda-

\footnotetext{
${ }^{3}$ Proyecto desarrollado durante el año 2010 y financiado por la dirección general de Política Forestal de la Consejería de Medio Rural y Pesca del Principado de Asturias.
} 
mentales cuya pertinencia se corroboró mediante un reconocimiento territorial de la red de caminos del cantón de los Grisones ${ }^{4}$, en Suiza.

\subsection{PRINCIPIOS PARA LA INTERVENCIÓN EN LAS VÍAS DE PAISAJE DE ASTURIAS}

Partimos del entendimiento de que es fundamental para la intervención responsable sobre el camino rural la adopción de un enfoque territorial, según el cual no se toma al camino como un artefacto aislado que se construye sin tener en cuenta el entorno que lo rodea, sino como parte de un sistema dinámico y frágil, el paisaje, con el que debe estar en armonía, a la cual contribuyen tres principios: el de integración, el de funcionalidad y el de adaptación.

Queda patente que el tiempo que hoy corremos permite a los hombres tan amplio abanico de opciones para librarse de la determinación del medio, que muchas de ellas constituyen severas amenazas al mismo, invirtiéndose la relación de determinación, que ahora pasa a ser ejercida por el hombre, que creyéndose libre de la necesidad, puede actuar con tal poder mecánico que aplasta momentáneamente al medio, degradando sus condiciones y capacidades. Extremar la cautela en las intervenciones físicas sobre los frágiles territorios rurales aspira a prevenir riesgos posibles y a contener la acción potencial dentro del marco que mejor convenga. Estando determinada esta conveniencia por el estudio territorial y la intervención razonada y compartida ampliamente, no sólo como garantía de armonía sino de corresponsabilización en su mantenimiento. La actuación sobre los caminos rurales puede guiarse con un doble objetivo: contribuir a dinamizar el tejido social y económico del mundo rural facilitando la movilidad sostenible, e integrarlos armónicamente en un recurso valioso como es el paisaje, que ellos contribuyen a dibujar.

Ante todo, el camino facilita la movilidad. Es un camino integrado en su entorno aquél que genera el menor impacto posible sobre el paisaje que lo rodea. Aquél que salva pendientes de forma suave, adaptándose a las formas de la topografía, utiliza materiales autóctonos y cuyos muros y cunetas se imbrican en la cubierta vegetal de modo que se vuelven apenas perceptibles. Tal principio puede entrar en contradicción con el de funcionalidad. Pero si entendemos camino como infraestructura que da servicio al medio rural, es indispensable que tenga una función o funciones determinada. Si el camino no es funcional carece de sentido, y para eso es mejor que no exista. Es imposible construir un camino sin impacto territorial, pues se trata de una construcción humana, tangible. Pero entendemos obligatorio buscar el máximo común divisor entre integración y funcionalidad. En tercer lugar, nos referimos al concepto de adaptación, que tiene que ver con el cumplimiento de la legalidad y afecciones vigentes sobre el camino. Desde la legislación de paisajes y de construcción de

\footnotetext{
${ }^{4}$ El cantón de los Grisones se encuentra en el extremo oriental de Suiza, limitando con el Tirol austríaco.
} 
infraestructuras hasta las formas de protección natural e hitos paisajísticos concretos. En tales principios se basan todas nuestras propuestas.

Entendemos irrenunciable adoptar una perspectiva territorial; por cuanto no es lo mismo construir un camino en una llanura esteparia que en una ladera escarpada, un acceso a una explotación maderera que una ruta de senderismo para uso recreativo. Por ello, hemos analizado los paisajes de Asturias, el modo en que la acción antrópica influye sobre cada uno de ellos, y establecido una clasificación de usos de los caminos, en función de la cual hemos organizado nuestra propuesta de buenas prácticas de intervención.

Figura 1. Esquema teórico para las recomendaciones de intervención en vías de paisaje.

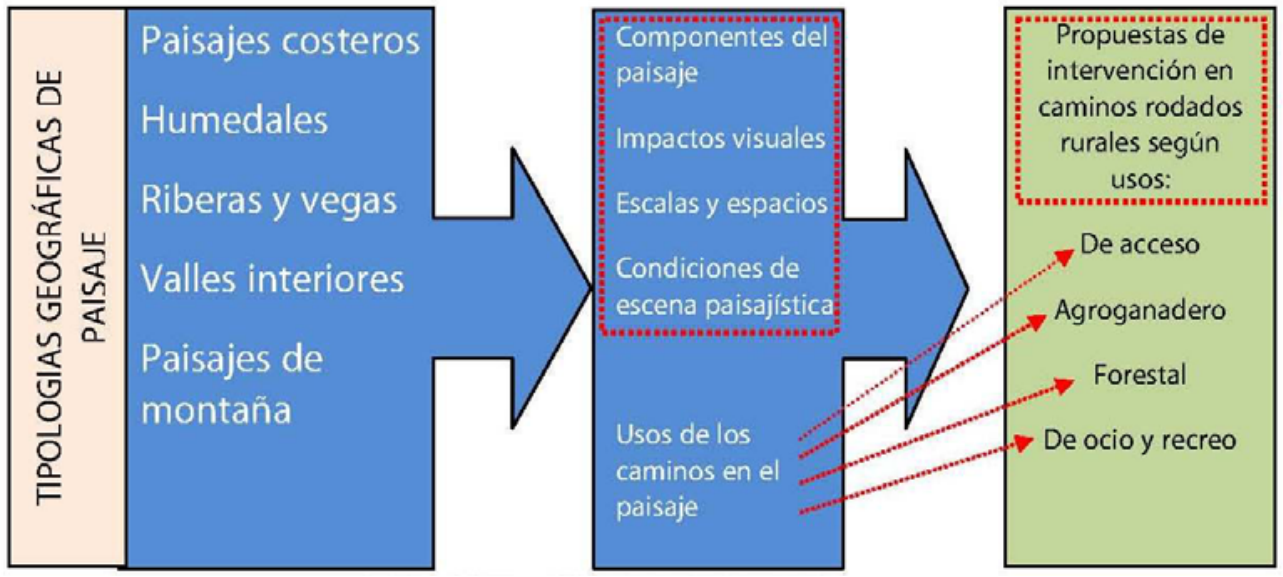

Fuente: CeCodet.

Clasificamos los caminos según su funcionalidad en los siguientes tipos: de acceso, agroganaderos, forestales y recreativos.

Los de acceso comunican poblaciones entre sí o con otros elementos antrópicos tales como paneles solares, molinos de viento o torres de comunicaciones. Los de uso agroganadero, probablemente los más extendidos en el medio rural asturiano, son aquellos que dan servicio a las actividades rurales tradicionales, como la comunicación con fincas agrícolas y el transporte de ganado. Entendemos por camino forestal aquél que se abre con el objetivo de explotar el bosque para la obtención de madera, y por camino recreativo aquél que por sus valores estéticos, culturales o de cualquier tipo es atractivo para la población, que acude a él para disfrutarlo recreativa, cultural o deportivamente. Estos últimos caminos soportan una demanda creciente, convirtiéndose en potencial puerta de entrada de actividad económica y dinamismo en torno de ellos.

Aunque la mayoría de caminos tienen un uso dominante que los define, es habitual que diferentes usos convivan en una vía. Las características del camino deberán adaptarse al aprovechamiento dominante que éste vaya a tener, sin excluir al resto. 


\subsection{BUENAS PRÁCTICAS DE INTERVENCIÓN EN SUIZA}

Suiza es un país montañoso, donde la configuración del terreno dificulta la obra del camino rural, y la explotación forestal y recreativa de los caminos cobra importancia junto a las actividades agroganaderas tradicionales. Con similitudes y diferencias respecto del paisaje asturiano, algunas de las experiencias allí observadas sobre el diseño, desarrollo y mantenimiento de los caminos rurales (distinguiendo entre aquellas que afectan a las políticas sectoriales y aquellas que tienen que ver con las técnicas y métodos de obra) podrían importarse a Asturias y España.

\subsubsection{POLÍTICAS SECTORIALES: EL PLAN FORESTAL SUIZO}

La financiación del coste de las obras es estatal o del cantón ${ }^{5}$, mientras que el mantenimiento y la adecuación de la red de caminos rurales corren a cargo de cada comuna $^{6}$. La figura más destacada de la política forestal suiza es la existencia del Plan Forestal. De dimensión comarcal, promueve la obtención de consensos entre la administración comunal, ganaderos, agricultores, sector maderero y otros, para la planificación de la red de caminos, que es gestionada por las oficinas forestales regionales.

Es fundamental apoyar la búsqueda de consenso en una herramienta que cuantifique las necesidades reales de actuación sobre la red caminera. En el caso del Plan Forestal, tal herramienta es un diagrama en el que se cuantifican numerosas variables relacionadas con los beneficios e impactos negativos que determinada obra puede causar para la comarca. El diagrama permite obtener una clasificación de qué obras son prioritarias dentro de la red comarcal, priorizando siempre la adecuación de caminos ya construidos a la obra nueva. Si bien tal clasificación no es vinculante, pudiendo acometerse antes obras peor clasificadas en función del deseo expreso de la autoridad local, cada proyecto de construcción o de ampliación de un camino necesita obtener un mínimo de puntuación para considerar su acometida.

El Plan Forestal suizo se ha confirmado como una herramienta muy eficaz. La búsqueda de un consenso con los agentes territoriales, las autoridades políticas y los diversos colectivos que participan en la selección de proyectos permite a la oficina forestal ejecutar obras que cuentan con el respaldo de la población y que se adecuan a las necesidades reales de la red. Se trata de una herramienta de enfoque territorial, eficiente, con resultados positivos en cuanto a la integración de los caminos en el paisaje, su funcionalidad y su razonable coste económico.

\footnotetext{
${ }^{5}$ Ente político y administrativo sobre el que se construye el estado nacional suizo. Se trata del escalón intermedio entre la Confederación y los municipios (comunas).

${ }^{6}$ Entidad territorial básica y de menor nivel en la división político-territorial de Suiza.
} 
Figura 2. Extracto del diagrama utilizado en el Plan Forestal suizo para establecer prioridades de actuación sobre la red de caminos comarcal ${ }^{7}$.

\begin{tabular}{|c|c|c|c|c|c|}
\hline & Protección: min. 0 Puntos, max. 50 Puntos $(0-5$ & Puntos & & TOTAL 1 - & -. \\
\hline \multirow{3}{*}{ 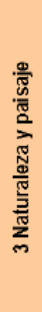 } & $\begin{array}{l}\text { 3.1 Conservación de la pérdida de área } \\
\text { Pérdida de las zonas VI sin cuidado (de WEP: } \\
\text { bosques o zonas con especiales objetivos } \\
\text { conservación de la naturaleza, paisajes valiosos } \\
\text { y formas de uso), debido a que cruzan o incisión }\end{array}$ & $m^{2}$ & $\begin{array}{l}<200 \\
200-500 \\
>500\end{array}$ & $\begin{array}{l}0 \text { Puntos } \\
-1 \\
-2\end{array}$ & - \\
\hline & $\begin{array}{l}\text { 3.2 Zonas urbanas de conservación } \\
\text { Tamaño de los suelos urbanos con prados secos } \\
\text { NS-cuidado (márgenes de los bosques } \\
\text { especiales, etc. según lista) }\end{array}$ & ha & $\begin{array}{c}>20 \\
5-20 \\
>0.1<5\end{array}$ & $\begin{array}{l}3 \\
2 \\
1\end{array}$ & - \\
\hline & \multicolumn{4}{|l|}{ Naturaleza y paisaje: min. -2 Puntos, max. 3 Puntos } & .. \\
\hline \multirow{5}{*}{ 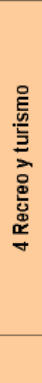 } & $\begin{array}{l}\text { 4.1 Acceso al edificio } \\
\text { Número de casa de fin de semana o de } \\
\text { vacaciones }\end{array}$ & Nr. & $\begin{array}{l}>5 \\
1-5 \\
\text { no }\end{array}$ & $\begin{array}{l}2 \text { Puntos } \\
1 \\
0\end{array}$ & -- \\
\hline & $\begin{array}{l}\text { 4.2 Ferrocarriles de montaña } \\
\text { Acceso a las instalaciones de empresas } \\
\text { ferroviarias }\end{array}$ & $\begin{array}{l}\text { si } \\
\text { no }\end{array}$ & $\begin{array}{l}\text { si: } \\
\text { no: }\end{array}$ & $\begin{array}{l}1 \\
0\end{array}$ & -- \\
\hline & $\begin{array}{l}\text { 4.3 Otras mejoras turisticas } \\
\text { Mejora general de las instalaciones turisticas } \\
\text { (conexiones con otros medios o equipos) }\end{array}$ & $\begin{array}{l}\text { Si } \\
\text { no }\end{array}$ & $\begin{array}{l}\text { no: } \\
\text { no }\end{array}$ & $\begin{array}{l}1 \\
0\end{array}$ & -- \\
\hline & \multicolumn{3}{|l|}{ Recreo y turismo: min. o Puntos, max. 4} & TOTAL 4 & -- \\
\hline & Criterio & Media & Valoración & & \\
\hline \multirow{4}{*}{ 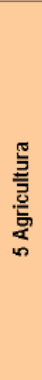 } & $\begin{array}{l}\text { 5.1 De los alpes y granjas alpinas } \\
\text { El número de los países desarrollados por el } \\
\text { bosque alpino / Participaciones }\end{array}$ & $\mathrm{Nr}$. & $\begin{array}{l}>4 \\
1-4 \\
\text { no }=0\end{array}$ & $\begin{array}{l}2 \text { Puntos } \\
1 \\
0\end{array}$ & -- \\
\hline & $\begin{array}{l}5.2 \text { Cabezas de Ganado mayor } \\
\text { Volumen de cabezas en granjas sin explotar }\end{array}$ & Nr. & $\begin{array}{l}>200 \\
50-200 \\
<50\end{array}$ & $\begin{array}{l}2 \\
1 \\
0\end{array}$ & -- \\
\hline & $\begin{array}{l}\text { 5.3 Prados de siega } \\
\text { Existencia de prácticas agrarias }\end{array}$ & ha & $\begin{array}{l}>40 \\
10-40 \\
<10\end{array}$ & $\begin{array}{l}2 \\
1 \\
0\end{array}$ & - \\
\hline & \multicolumn{3}{|l|}{ Agricultura: min. 0 Puntos, $\operatorname{max.6)}$} & TOTAL 5 & .. \\
\hline
\end{tabular}

Fuente: Traducción a partir de diagrama de Oficina Forestal de los Grisones (Suiza).

\subsubsection{TÉCNICAS Y MÉTODOS DE OBRA}

El bosque suizo, compacto y tupido, formado casi exclusivamente por coníferas, donde los límites con praderías y pastos alpinos están bien definidos, facilita el desarrollo e integración de los caminos forestales en la cubierta vegetal arbórea que, por lo general, alcanza mayores altitudes que en España. En cuanto a técnicas constructivas,

\footnotetext{
${ }^{7}$ Incluye una serie de categorías (producción de madera, protección medioambiental, naturaleza, recreo y turismo, agricultura, costes, otros) a las que se otorgan puntuaciones siguiendo criterios claros y consensuados.
} 
las vías se adaptan a las formas del monte, evitando la generación de grandes pendientes que, además de aumentar los gastos de mantenimiento por escorrentía y aumento de la seguridad vial, causan impactos severos sobre el paisaje al no adaptarse a las formas preexistentes. Se trata por lo general de caminos que cumplen su función mimetizándose con el entorno.

Tanto los firmes como los elementos de drenaje, escolleras, y otros proceden en su gran mayoría del medio natural más cercano. Los áridos se extraen controladamente de los cursos de agua y se aprovechan para el firme, y la madera de conífera se utiliza en la construcción de puentes, muros y drenajes. La integración constructiva es alta, pues los materiales son autóctonos, lo que trae beneficios para el medio ambiente incluso a kilómetros de distancia, puesto que apenas hay canteras en territorio suizo.

Es poco habitual la utilización de hormigón en los firmes o para la estabilización de pendientes, salvo en accesos a fincas particulares y puntos concretos donde puede facilitar la tracción de vehículos. En el caso particular de laderas con problemas de estabilización, se suele facilitar la colonización vegetal de los taludes, mediante tipologías como los muros krainer, en los que, mediante el apilamiento de troncos, se contribuye a fijar la vegetación y el suelo, favoreciendo al mismo tiempo la integración del camino en su entorno. También se usa madera local en la construcción de puentes y drenajes, que se emplean con mayor profusión que en los caminos españoles. Apenas se instalan elementos de iluminación excepto en áreas pobladas, y la señalización suele ser escasa y clara.

Figura 3. El impacto paisajístico de la actividad forestal ${ }^{8}$
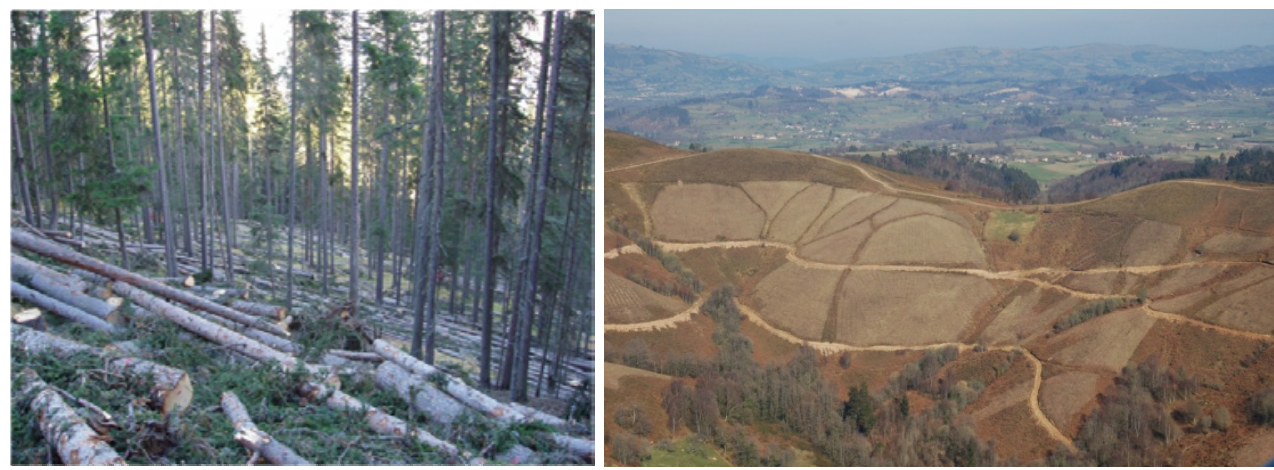

Fuente: Archivo fotográfico CeCodet.

\footnotetext{
${ }^{8}$ El impacto paisajístico de la actividad forestal es mucho menor si se realiza tala selectiva (cantón de los Grisones, Suiza, izq.) que si se talan parcelas enteras de monte (Nava, Asturias, dcha.). Los caminos también se integrarán más fácilmente en montes donde se practique la tala selectiva.
} 
Otra buena práctica para la protección del paisaje habitual en Suiza es la práctica de la tala selectiva. Consiste en la extracción de un número determinado de árboles de una mata, dejando en pie la cantidad suficiente para no alterar las condiciones del monte y su aspecto físico. Aparte de disminuir el impacto de la explotación forestal, garantiza la permanente accesibilidad a la madera en cualquier punto de la mata, tanto para la construcción y mantenimiento de los caminos como para la explotación.

\subsection{PROPUESTA DE BUENAS PRÁCTICAS EN ASTURIAS}

A partir de los principios para la intervención en vías de paisaje de Asturias (integración, funcionalidad y adaptación), de las tipologías de caminos delimitadas, y de las buenas prácticas observadas en Suiza, se proponen buenas prácticas para la construcción de caminos en Asturias, que a su vez, y con las correspondientes adaptaciones a las particularidades de cada región, pueden servir como punto de partida para el establecimiento de unas buenas prácticas válidas en todo el territorio español.

\subsubsection{IMPORTACIÓN Y ADAPTACIÓN DEL PLAN FORESTAL}

Un Plan Forestal convenientemente desarrollado en esta materia permitiría fijar criterios objetivos para regular el trazado y diseño de caminos rurales, así como para evaluar prioridades de intervención en determinado territorio. Sería conveniente inspirarse en las metodologías vistas en Suiza que, a lo largo de los años, se han probado acertadas tanto económica como paisajísticamente. Uno de los pilares en que debe asentarse el Plan Forestal es la inclusión en el proceso de toma de decisiones de todos los sectores interesados en el uso y aprovechamiento de los caminos rurales, pues de lo contrario la figura puede nacer mermada al traicionar uno de sus principios fundamentales. En Asturias existe redactado el Plan Forestal que dedica página y media a la Red de vías forestales de base municipal sencillamente jerarquizada en su interior en tres niveles dentro de una estructura de diez comarcas forestales y para el cual se anuncia una pronta revisión, momento oportuno para introducir estos aspectos si se consideraran pertinentes. Proponemos para el Plan un desarrollo tomando como referencia la escala comarcal, la misma que se ha probado exitosa en Suiza, siempre que se tengan en cuenta el resto de escalas ${ }^{9}$ en que debe plantearse la actuación sobre caminos y la relación de estos con su entorno, pues es evidente que puede formalizarse una red, que integra desde los grandes caminos-colectores a los caminos de acceso intraparroquiales.

\footnotetext{
${ }^{9}$ La parroquial, pues en la orografía montañosa del principado de Asturias las células parroquiales eran las unidades elementales para la ordenación del territorio, la municipal e incluso la regional para los grandes caminos-colectores
} 
La adopción de unas normas de juego iguales para todos ha de ser necesariamente beneficiosa a la hora de gestionar las redes de caminos con sentido común y conforme a unos principios consensuados. Del consenso deben partir también aquellos criterios de decisión que se fijen para establecer prioridades de actuación sobre la red de caminos, atendiendo a variables como la rentabilidad de la infraestructura, los costes de obra y la integración paisajística.

\subsubsection{CRITERIOS PARA LA CONSTRUCCIÓN DE CAMINOS RURALES EN ASTURIAS}

Los caminos deben dar respuesta a las necesidades tradicionales de un medio rural en declive demográfico y de actividad, a la vez que se optimiza su integración en el paisaje del que forman parte y se procura dar cobertura a nuevas oportunidades de desarrollo (explotación forestal, turismo, senderismo, deporte de aventura) en una tendencia de multifuncionalidad. Partiendo de una interpretación del camino como resultado de la interacción de variables históricas, culturales y socioeconómicas, no será posible lograr su integración, adaptación y funcionalidad sin tenerlas en cuenta a todas ellas. Los criterios reunidos en este epígrafe pretenden cumplir con tal aspiración. Organizamos esta propuesta de buenas prácticas en función de los componentes del camino, que son el piso, el zócalo y la cubierta.

El ancho de la caja del camino que debe abrirse sobre el terreno se corresponde con el componente piso. Lo forman el firme, parte más visible de la vía, la señalización horizontal si la hubiera, el tratamiento y drenaje de aguas, y aceras y bordillos.

Siguiendo el modelo suizo, se opta por actuaciones que primen la integración de la obra en el entorno. Pese a la dificultad técnica que en Asturias tal pretensión puede acarrear, por la intensa ondulación de su territorio, se recomienda la limitación de las pendientes siempre que sea posible a un máximo del $20 \%$ y que la utilización de pavimentos sigan el principio de integración. En primer lugar, porque limitar las pendientes permite utilizar zahorras y materiales autóctonos, restringiendo el uso de hormigón a pendientes superiores donde no haya alternativa. Al mismo tiempo, se limita el impacto paisajístico de las vías, al adaptarse éstas con mayor naturalidad a las formas del relieve, se mejoran las condiciones de seguridad por la suavidad de sus pendientes y se disminuyen los costes de mantenimiento por escorrentía.

El ancho será el mínimo imprescindible que garantice las funciones para las que ha sido diseñada la vía con las suficientes condiciones de seguridad. Es decir, en caminos con intensidad baja de uso en los que el cruce de vehículos sea esporádico, bastará un ancho de un carril, habilitándose apartaderos en determinados puntos. Con esta medida se reducen el impacto del camino, la eliminación de la cubierta vegetal y los desmontes, rellenos y taludes. A menor ancho de camino, menor coste de obra y de cesión de tierras. 
Figura 4. La adaptación del camino a las curvas de nivel favorece la integración del mismo ${ }^{10}$.

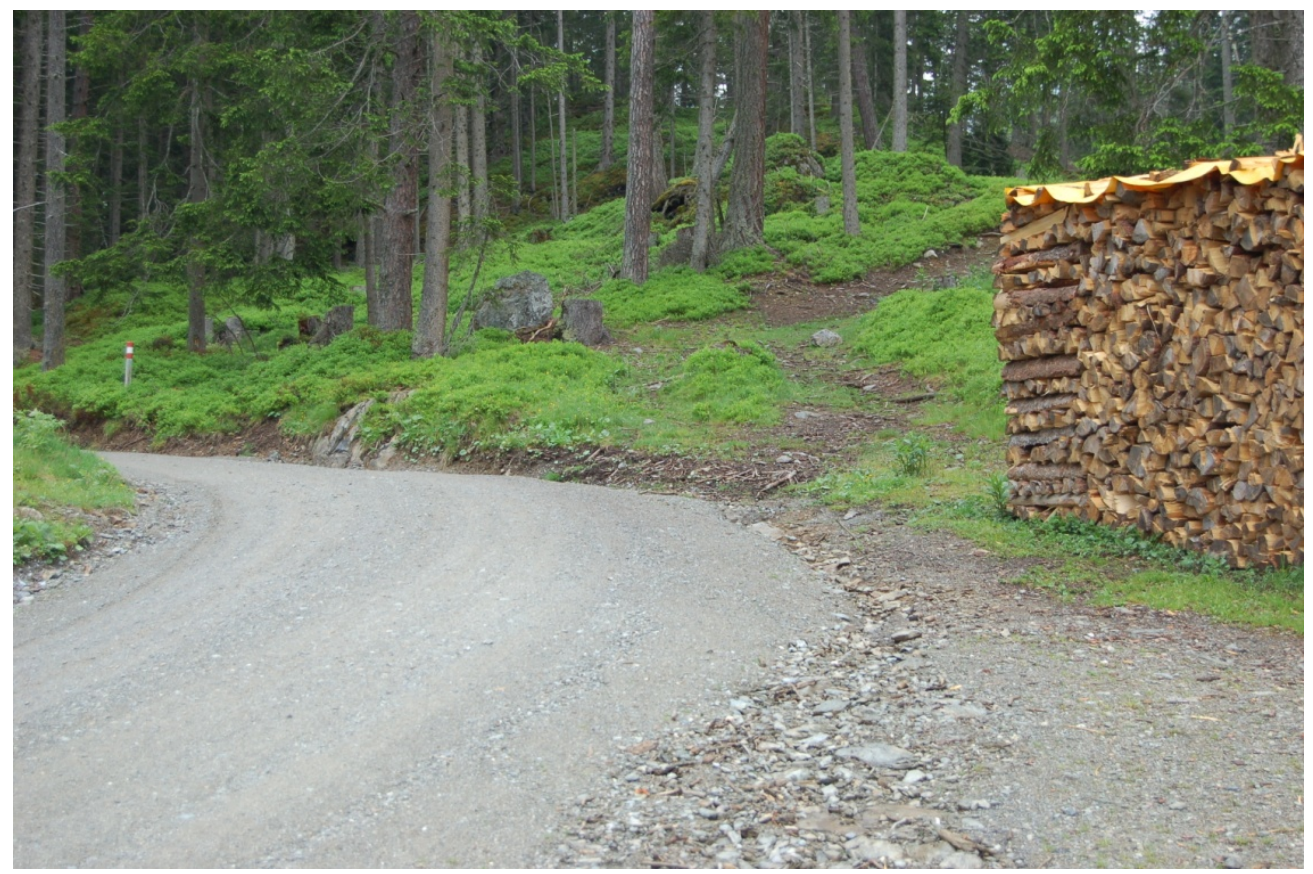

Fuente: Archivo fotográfico CeCodet.

Se considera buena práctica la utilización de materiales discretos en la construcción de cunetas y sumideros, y que la inclusión de bordillos y aceras no es necesaria en la mayoría de los casos. Teniendo en cuenta que la infraestructura se insertará en un medio rural, donde la disposición de los elementos del paisaje tiende a ser orgánica, irregular, se reducirá al máximo la presencia de elementos como papeleras, bancos, puntos de iluminación, postes y señales. Cuantos menos elementos tenga el camino y más orgánica sea su disposición, mayor será su integración en el medio natural. A ello puede contribuir la instalación de pantallas vegetales en torno del piso.

Llamamos zócalo a la franja comprendida entre el piso y 1,5 mts. de altura. Comprende elementos como el mobiliario, la señalización, seguridad, cierres de fincas, taludes y accesos.

\footnotetext{
${ }^{10}$ La adaptación del camino a las curvas de nivel favorece la integración del mismo, al evitarse introducir formas antinaturales en el paisaje. También evita el uso de hormigón en el firme al reducir los problemas de escorrentía.
} 
Figura 5. Es recomendable no introducir elementos de seguridad a menos que sea absolutamente necesario ${ }^{11}$.

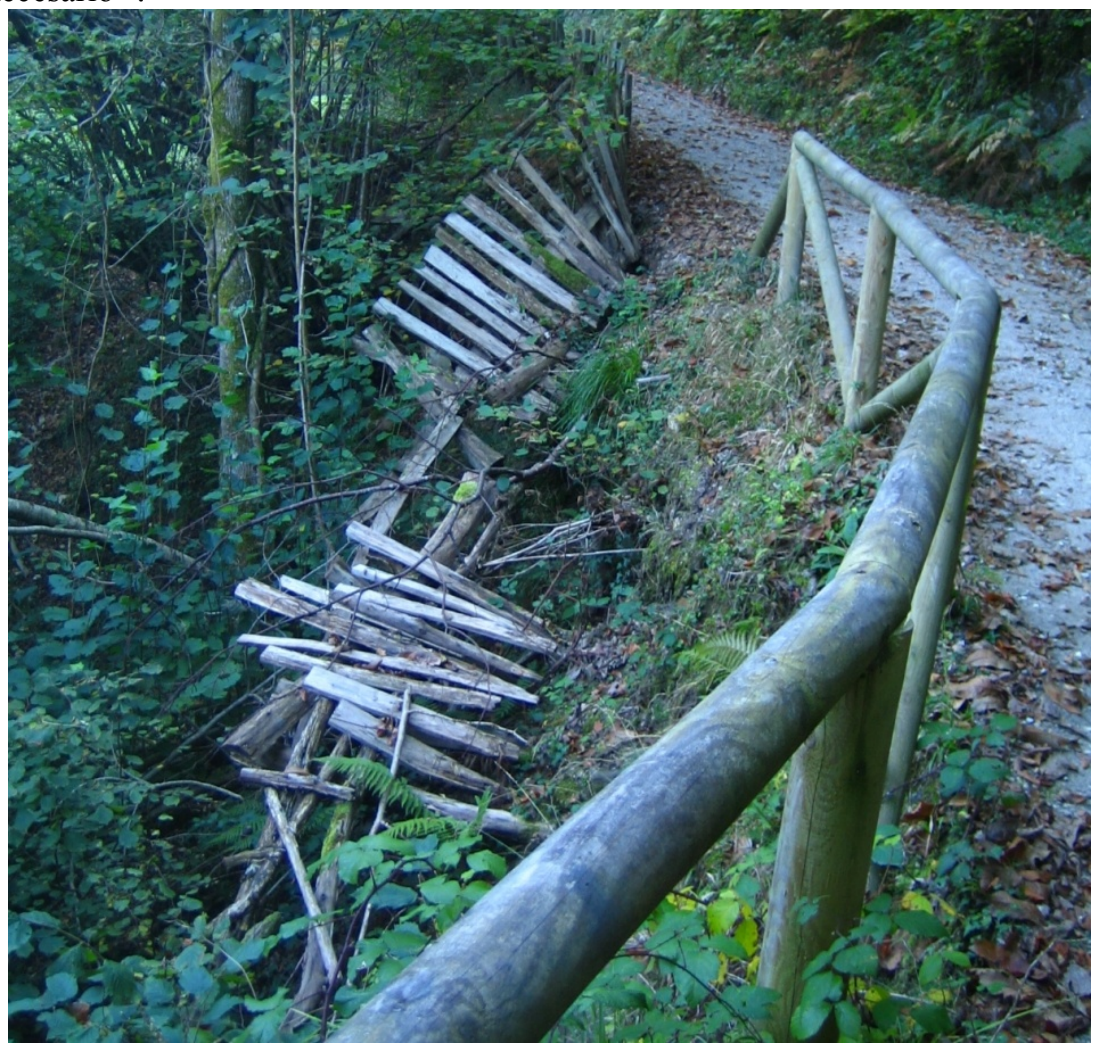

Fuente: Archivo fotográfico CeCodet.

Se recomienda restringir el uso de elementos del zócalo a lo necesario, puesto que el único componente irrenunciable del camino es el firme, y los elementos que lo rodean habrán de responder a necesidades concretas. Cualquier influencia humana en el medio natural debe realizarse con la mayor sencillez posible. Es por ello por lo que se plantea limitar el uso de mobiliario y elementos de seguridad, que únicamente aparecerán como medida preventiva para riesgos tangibles del camino y, en su caso, deberán tener un mantenimiento estricto. También se recomienda conservar los cierres tradicionales de fincas en torno de la vía, pues son elementos valiosos de patrimonio popular que dan personalidad al paisaje, y evitar la construcción de muros

\footnotetext{
${ }^{11}$ Es recomendable no introducir elementos de seguridad a menos que sea absolutamente necesario. En tal caso, su estado de mantenimiento habrá de ser excelente en todo momento, si no queremos multiplicar el riesgo preexistente.
} 
de hormigón, siendo preferibles tipologías de muro en material autóctono y que faciliten la colonización vegetal.

Figura 6. El muro krainer reduce el impacto de la obra al hacerse con materia vegetal, lo que favorece su rápida colonización y mimetización con el terreno.

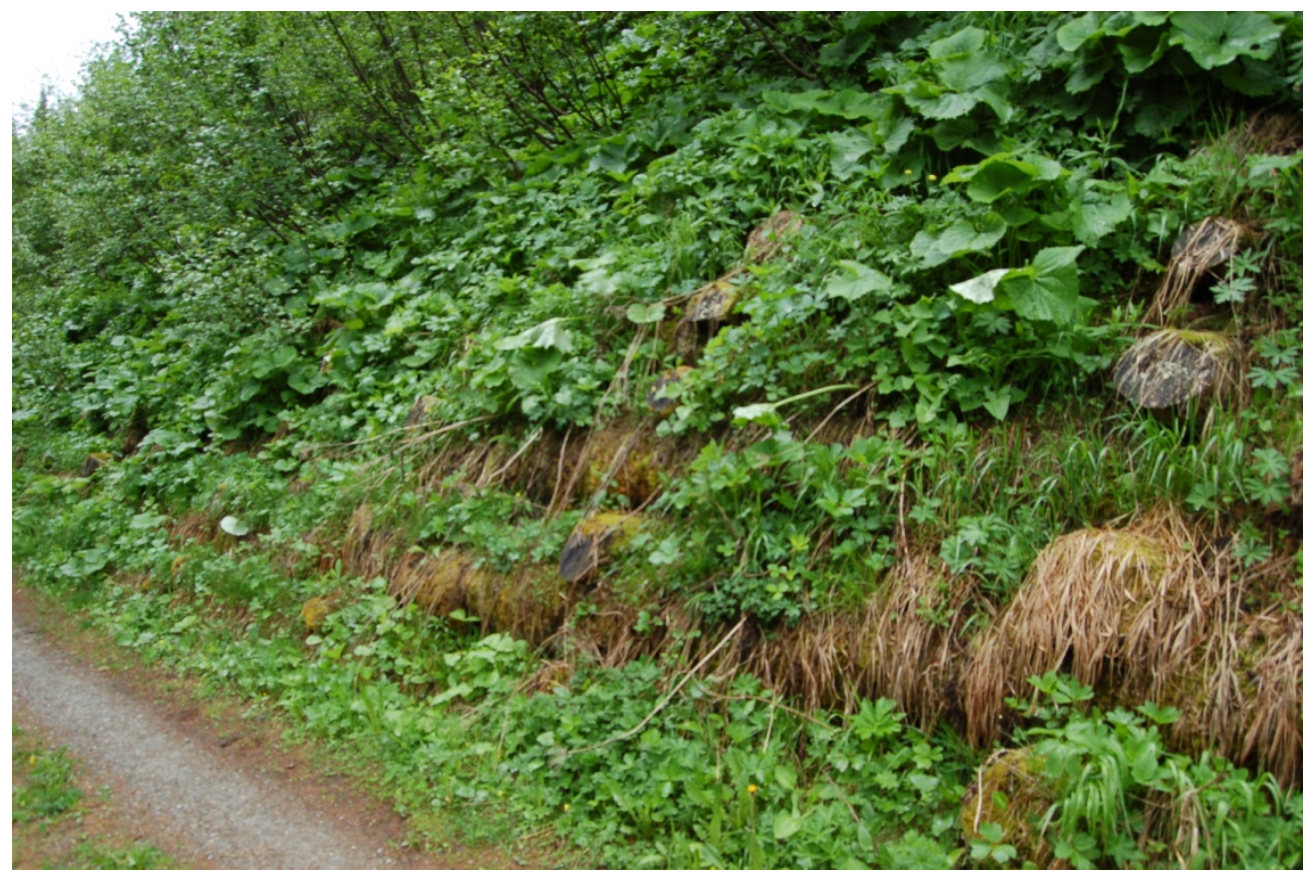

Fuente: Archivo fotográfico CeCodet.

En cuanto a la señalización, se considera urgente el desarrollo de un sistema normalizado a escala interregional o nacional, puesto que, como muchos otros aspectos relacionados con el camino rural, existe un vacío en la reglamentación que favorece desigualdades y resta calidad a la red. Se considera que ésta debe ser escasa y comprensible.

Cubierta es la franja en torno del camino y por encima de él que se encuentra por encima de 1,5 m. de altura, y comprende tendidos de infraestructuras e iluminación y arbolado.

El material más adecuado para los postes que deban instalarse es la madera, por su mayor integración con el medio, siendo preferible unificar la mayor cantidad posible de servicios en un solo poste para reducir el impacto de los tendidos, que se instalarán preferiblemente en el lado más construido del camino, favoreciendo la conservación del otro. La iluminación artificial genera gasto económico y contaminación lumínica, y aumenta el impacto de las actuaciones, con lo que su instalación se limitará a áreas 
habitadas. La introducción de arbolado en el contacto entre el camino y el paisaje circundante puede atenuar el impacto visual de la vía y favorecer su integración.

Figura 7. Ficha de buenas prácticas para caminos de uso forestal ${ }^{12}$.

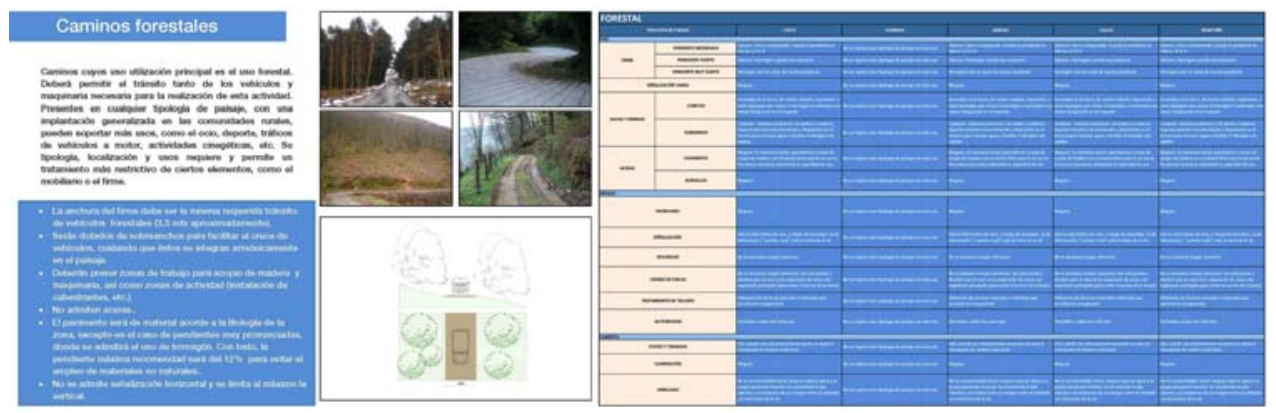

Fuente: CeCodet.

Todos estos criterios de intervención sobre piso, zócalo y cubierta se han barajado y adaptado a las tipologías de caminos establecidas, redactándose fichas de buenas prácticas para caminos de acceso, de uso agroganadero, forestales y recreativos.

No tiene sentido actuar sobre las redes de caminos atendiendo a principios de funcionalidad e integración si olvidamos el coste de las actuaciones y no se establecen programas de mantenimiento que garanticen la longevidad de las obras. Parece pertinente establecer costes máximos de obra asumibles en función de las dimensiones, usos y características de cada tipología de camino, de modo que las actuaciones no se disparen en su presupuesto. A ello contribuyen los criterios generales enunciados, que tienden a minimizar la introducción de materiales foráneos y a limitar a lo estrictamente necesario las actuaciones sobre el paisaje. La introducción de partidas económicas anuales destinadas al mantenimiento de la red de caminos, aunque suene paradójico, puede contribuir a la aspiración de contener el gasto, pues muchas veces el mal mantenimiento de los caminos ya construidos hace que, a la larga, deban acometerse nuevas construcciones de infraestructura que serían innecesarias con una inspección periódica del estado de los trazados.

Tampoco tiene sentido que la inversión en investigación y desarrollo sea de las primeras en caerse de los presupuestos en épocas de ajuste económico. Entendemos que es más sostenible invertir en el desarrollo de un Plan Forestal, o una figura parecida, y en el mantenimiento de una red de caminos funcional e integrada que en actuaciones aisladas y carentes de una estrategia consensuada. $\mathrm{Y}$ entendemos que es

\footnotetext{
${ }^{12} \mathrm{El}$ anverso (izq.) incluye consideraciones generales acerca de esta tipología de caminos, las recomendaciones de intervención más destacadas y fotografías y figuras que las ilustran. En el reverso (dcha.) se incluye el listado completo de recomendaciones para cada componente del camino. Se ha elaborado una ficha de buenas prácticas para cada tipología de camino según su uso
} 
mejor unir a todos bajo un hilo normativo conductor y un interés común que moverse a base de impulsos desordenados, donde el error es más probable y tiene consecuencias.

\section{HERRAMIENTAS METODOLÓGICAS PARA LA GESTIÓN INTEGRAL DE LAS REDES CAMINERAS RURALES ${ }^{13}$}

En el marco del proyecto Aprovechamiento del potencial de los caminos rurales de España (CRES) se perfiló una serie de herramientas metodológicas referidas a la gestión y construcción de caminos rurales cuya validez fue probada sobre el terreno. Participaron en la experiencia grupos de investigación, instituciones y empresas de Asturias, Galicia y Navarra.

\subsection{UNA VISIÓN COMPARTIDA: EL PROYECTO CRES, CAMINOS RURALES DE ESPAÑA}

En el proyecto CRES se ofrecen aportaciones para la mejora de la gestión de las redes de caminos rurales de España. Se procuró que el proyecto tuviera el mayor alcance posible, involucrando a todos los estamentos relacionados con los caminos rurales y estableciendo redes de colaboración entre territorios españoles, mediante una estructura de equipos de investigación de tres comunidades autónomas, desde las comarcas rurales de Pontevedra hasta los caminos históricos de Navarra, pasando por cinco concejos, muy diversos en cuanto a su tipología, de Asturias.

El objetivo básico del proyecto era desarrollar metodologías de intervención en caminos rurales susceptibles de convertirse en normales a escala estatal. Tales metodologías se aplican a las tres fases de la vida del camino (pre-proyecto, proyecto de obra y reformas, y gestión posterior). Aún con las limitaciones lógicas de una primera aproximación a tan compleja materia, entendemos que las aportaciones que a continuación se presentan suponen un punto de partida válido para un hipotético desarrollo legal de una política de gestión e intervención de las redes de caminos rurales españolas.

\footnotetext{
${ }^{13}$ Desarrolladas en el marco del proyecto Aprovechamiento del potencial de los caminos rurales de España (CRES) realizado durante el año 2011, impulsado por la Consejería de Medio Rural y Pesca del Principado de Asturias y financiado por el Fondo Europeo Agrícola de Desarrollo Rural (FEADER) y el Ministerio de Medio Ambiente y Medio Rural y Marino de España.
} 
Figura 8. Participantes en el proyecto CRES.

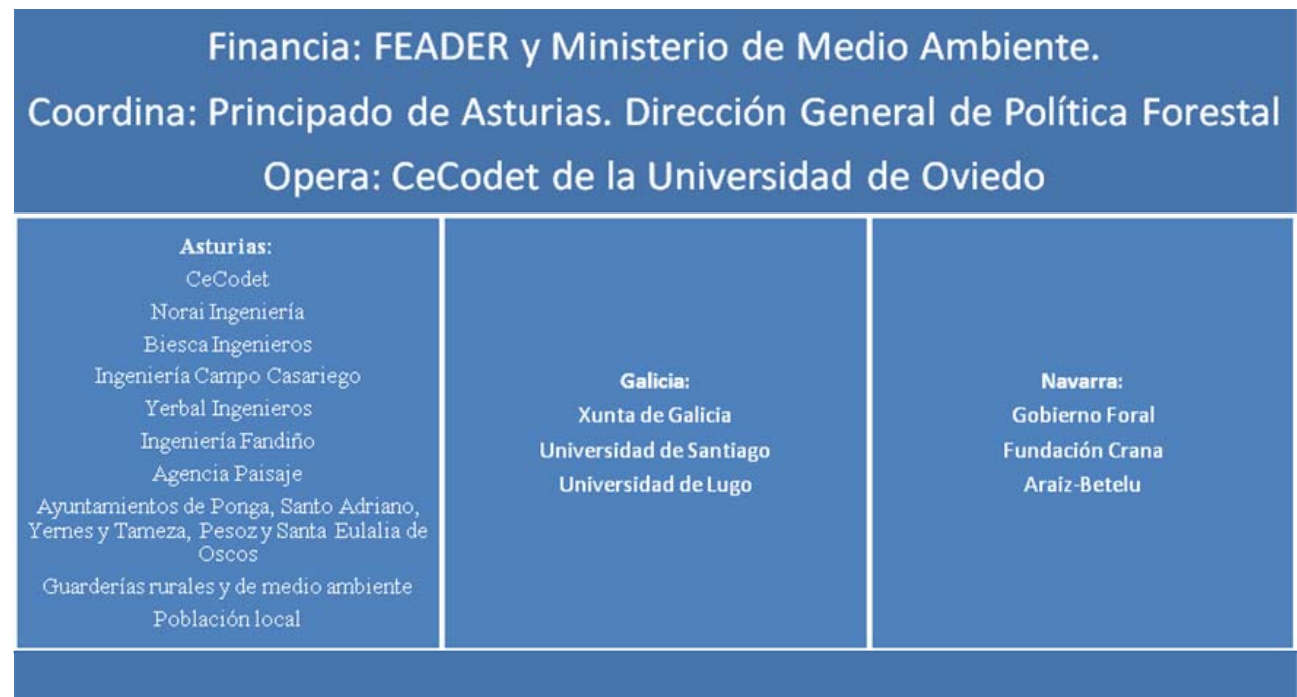

Fuente: CeCodet.

El marco metodológico elaborado en CRES encontró aplicación práctica, cumpliendo con los principios de integración, funcionalidad y adaptación, que entendemos irrenunciables. Desde CeCodet se trabajó en el desarrollo de metodologías de reconocimiento, identificación y toma de decisiones y obra de caminos, mientras que las universidades de Santiago de Compostela y Lugo investigaron la funcionalidad de los caminos, y el Centro de Recursos Ambientales de Navarra se centró en aspectos de la gestión posterior a la obra como la señalización y el mantenimiento.

\subsection{PROPUESTAS METODOLÓGICAS PARA LA GESTIÓN INTEGRAL DE CAMINOS RURALES Y SU APLICACIÓN}

Tales propuestas se hacen con el ánimo de constituir un punto de partida, no un destino final. Es necesario perfeccionar los métodos propuestos, adaptándolos a cada territorio. Por ello, durante el desarrollo del proyecto consideramos que era fundamental probar la validez de las metodologías que se estaban proponiendo, en un proceso que permitió ver sus puntos débiles e irlas mejorando a medida que se avanzaba en el trabajo. Por eso, las aportaciones de CRES no se limitan a desarrollos teóricos, sino que estos se ven completados por su correspondiente aplicación práctica. 


\subsubsection{RECONOCIMIENTO E IDENTIFICACIÓN DE LOS CAMINOS RURALES DE CINCO CONCEJOS ASTURIANOS}

Durante la fase de análisis de la red de caminos de un territorio es necesario reunir la mayor cantidad de información posible, para que la posterior toma de decisiones de intervención pueda realizarse con una base razonable. Para facilitar dicha tarea, se ha desarrollado un modelo normalizado de ficha de inventario y un sistema de información geográfica de caminos rurales. La funcionalidad de ambas herramientas se ha probado con éxito en cinco municipios de Asturias. La metodología de reconocimiento e identificación se realiza en tres pasos.

El primero es el que denominamos reconocimiento previo o recogida de información de base. Consiste en la explotación de fuentes públicas de información para elaborar una cartografía básica de la red de caminos que, en el caso del proyecto CRES, se hizo a escala municipal ${ }^{14}$. Para la elaboración de los mapas municipales de caminos se han empleado como base capas del Mapa Topográfico Nacional (MTN) 1:25000 y la ortofotografía aérea más reciente del Plan Nacional de Ortofoto Aérea (PNOA), pues ambas se encuentran disponibles para descarga gratuita en internet ${ }^{15}$. Del MTN se aprovechan capas de información básica del terreno (caminos, carreteras, ríos, núcleos de población, curvas de nivel) que permiten una primera aproximación cartográfica al municipio estudiado. La escala 1:25.000, empleada también en el Plan Forestal suizo, la hemos considerado la más adecuada para trabajar a escala municipal. Sucede que la edición del MTN disponible en internet data de 1994. Casi dos décadas de antigüedad generan un desfase entre la red de caminos representada en el mapa y la actual, tanto por la desaparición de caminos existentes en 1994 como por la alteración del trazado caminero previo por actuaciones diversas como por ejemplo concentraciones parcelarias. Para dar mayor precisión a la cartografía básica se emplea la ortofoto aérea del PNOA, cuya mayor actualidad ${ }^{16}$ y elevado nivel de detalle permiten trabajar con más precisión, matizando los errores que puede contener el MTN. En esta fase también se tienen en cuenta las figuras de protección ambiental que afectan al municipio, para adaptar las posibles actuaciones a tales afecciones.

Al segundo paso lo denominamos recogida de información a nivel municipal. En él, se comparte la cartografía básica municipal generada mediante la explotación del MTN y el PNOA con administración local, agentes de guardería, usuarios y eruditos

\footnotetext{
${ }^{14}$ Si bien proponíamos la escala comarcal para la implantación en España del Plan Forestal, a efectos del proyecto CRES se consideró más adecuado utilizar la escala municipal, pues de esta manera resultó más sencillo movilizar a las administraciones locales y la validez de las metodologías propuestas pudo probarse en una mayor diversidad de entornos.

${ }^{15}$ En la sección Centro de descargas de www.ign.es

${ }^{16}$ La última edición completa pertenece a 2009, con actualizaciones de 2011.
} 
locales. Esto permite afinar el detalle de la cartografía y empezar a dar contenido a lo que hasta ese momento únicamente son líneas pintadas sobre un mapa. Del contacto con regidores, profesionales y población local se obtiene información valiosa acerca de qué errores contiene la información básica, qué uso tienen los diferentes caminos y cuáles son de mayor o menor importancia para el municipio, quedando lista la base cartográfica para su empleo sobre el terreno en el tercer paso del reconocimiento e identificación de la red de caminos.

Figura 9. Ficha de inventario de caminos rurales (extracto) $)^{17}$.
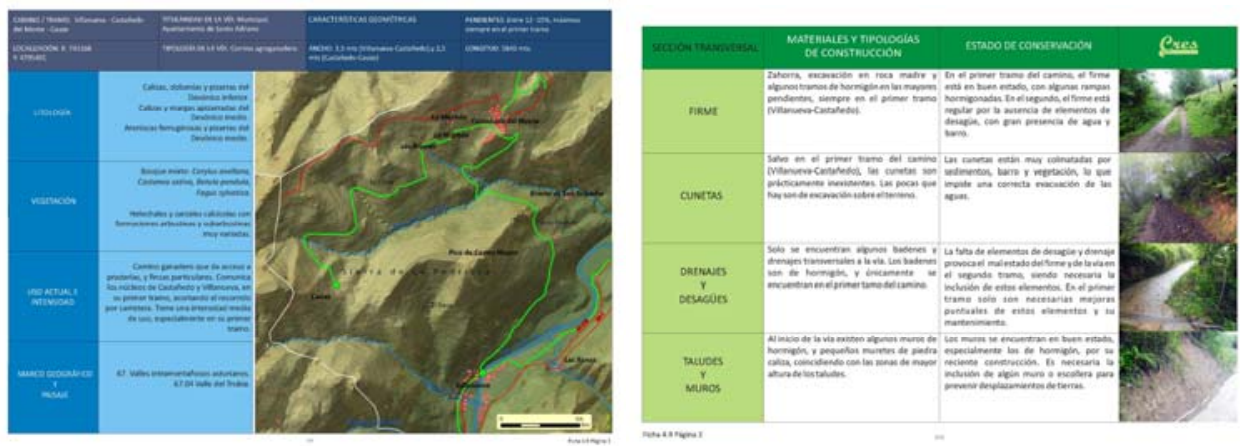

Fuente: CeCodet.

Durante el trabajo de campo, los investigadores recorren la red caminera municipal completa, equipados con GPS, cámaras de fotos y fichas de inventario. En este paso se dota de contenido a la cartografía básica desarrollada durante los dos anteriores: cada línea pintada que representa un camino se recorre, fotografía y analiza en profundidad, detectando el estado de cada vía, los elementos que la componen y las buenas y malas prácticas realizadas sobre ella. Para facilitar el trabajo, y ante la falta de herramientas similares, se ha desarrollado desde cero una ficha de inventario que recoge toda la información de interés de cada camino para detectar necesidades de intervención. Mediante el trabajo de campo y la cumplimentación de la ficha de cada camino se reúne un elevado volumen de información acerca del estado de la red caminera de los municipios, que se vuelca a un Sistema de Información Geográfica (SIG) de caminos rurales. En el SIG pueden consultarse sobre el mapa municipal todos los atributos y características reunidos durante el trabajo de campo. Tanto las exhaustivas fichas de inventario como el SIG de caminos se ponen en manos de

\footnotetext{
${ }^{17}$ En la página uno (izq.) se presentan atributos básicos del camino inventariado, tales como nombre, uso, titularidad, ancho, longitud, pendientes, características del paisaje y cartografía. En las páginas dos (dcha.) y tres, se hace un análisis de todos los componentes del camino, divididos en piso, cubierta y zócalo. Para cada componente se reseñan los materiales y tipologías de construcción, su estado de conservación, y se incluyen fotografías. Todos los atributos incluidos en esta ficha se vuelcan a un Sistema de Información Geográfica de la red de caminos municipal.
} 
administraciones, empresas y usuarios, permitiendo que el proceso de debate y toma de decisiones de intervención pueda realizarse con información abundante.

Figura 10. Camino de acceso a una torre de comunicaciones cerca de Carangas (Ponga) ${ }^{18}$.

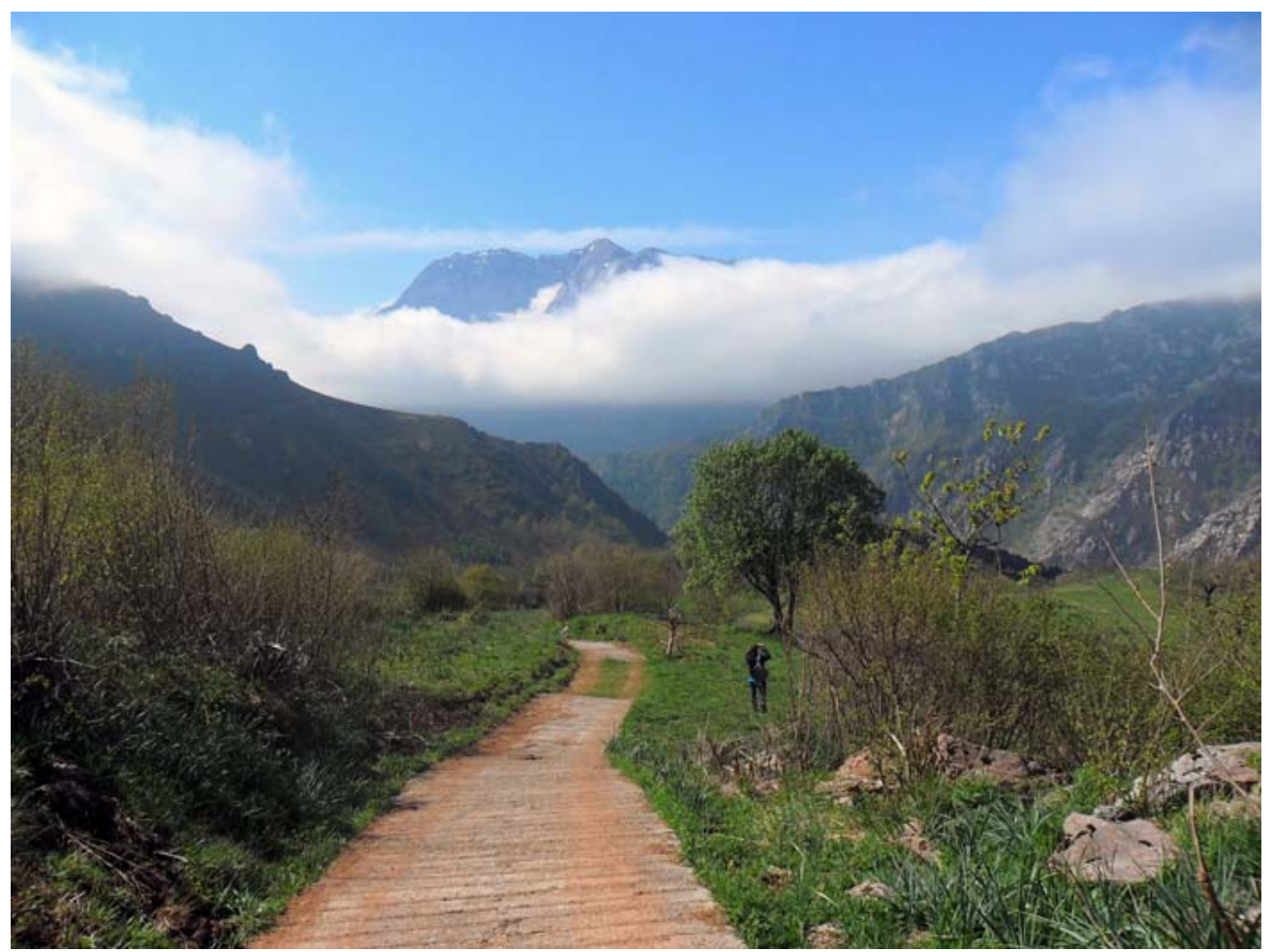

Fuente: Archivo fotográfico CeCodet.

La prueba de esta metodología de reconocimiento e identificación se realizó en los concejos asturianos de Ponga, Santo Adriano, Yernes y Tameza, Pesoz y Santa Eulalia de Oscos. Tuvo lugar entre marzo de 2011 y junio de 2011, con más de cuarenta jornadas de inventariado, a las que deben sumarse las salidas previas para el reconocimiento general de las redes y las reuniones con las corporaciones locales y oficinas de las guarderías. Estos municipios fueron escogidos por pertenecer a entornos paisajísticos diferentes, y por contar con necesidades diversas y caminos de distintas tipologías, siempre dentro de un

\footnotetext{
${ }^{18}$ Durante la fase de trabajo de campo de CRES se probó la validez de las herramientas metodológicas propuestas, analizándose en detalle caminos de diferentes usos y tipologías del medio rural asturiano.
} 
carácter netamente rural. En total, se inventariaron en detalle 89 caminos que suman más de 250 kilómetros de longitud, durante los que pudo comprobarse la validez de las fichas para el objetivo para el cual fueron diseñadas.

\subsubsection{EL PROCESO DE TOMA DE DECISIONES DE INTERVENCIÓN}

El abundante material recogido en las fichas de inventario y el sistema de información geográfica son las herramientas que se proponen como base para la toma de decisiones de mejora de la red de caminos. En el proceso deben participar las administraciones locales y regionales, los usuarios, los sectores económicos interesados y los técnicos. Las decisiones definitivas deben ser justificables en relación con los resultados del reconocimiento e identificación, y surgir del debate, del intercambio de conocimientos y opiniones y de las necesidades concretas de cada red de caminos y de cada territorio.

Figura 11. Proceso de toma de decisiones de intervención sobre la red de caminos ${ }^{19}$.

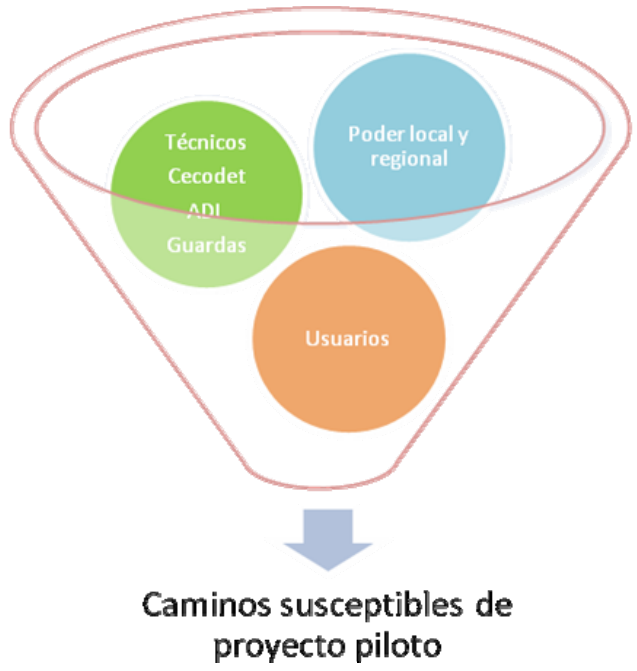

Fuente: CeCodet.

Junto a las fichas de inventario y el sistema de información geográfica deben tenerse en cuenta los testimonios de técnicos conocedores de los ámbitos de actuación,

\footnotetext{
${ }^{19}$ Las fichas y el sistema de información geográfica desarrollados se ponen al servicio de todos los agentes interesados en la red como instrumento base para la búsqueda de consenso.
} 
como los guardas rurales y de medio ambiente y los agentes de desarrollo local, así como a las empresas de ingeniería designadas para realizar los proyectos de obra, puesto que ellas tendrán la última palabra sobre la viabilidad técnica de los proyectos y los presupuestos necesarios. Las administraciones local y regional son fundamentales para el proceso de toma de decisiones. El poder local conoce de primera mano el estado de la red de caminos y las necesidades del concejo, mientras que el regional juega un papel decisivo orientando las actuaciones, destinando las partidas económicas y asesorando el proceso.

Finalmente, no debe obviarse el testimonio de los usuarios, puesto que garantizar la funcionalidad del camino pasa por escuchar las necesidades de sus usuarios, desde agricultores y ganaderos a empresas de explotación maderera pasando por habitantes del medio rural. Es a ellos a quienes van destinadas las actuaciones, por lo que deben tenerse en cuenta sus puntos de vista, haciéndoles partícipes de un proceso basado en el debate y el consenso entre las partes implicadas.

Mediante la aplicación del procedimiento descrito se decidieron las intervenciones incluidas en el siguiente epígrafe, en cada uno de los cinco municipios asturianos utilizados como banco de pruebas del proyecto.

\subsubsection{PROYECTOS PILOTO DE BUENAS PRÁCTICAS EN ASTURIAS}

El resultado más tangible de CRES en Asturias fue la redacción por parte de cinco empresas de ingeniería de un proyecto de obra listo para ejecutar en cada concejo donde se realizó el ensayo de las metodologías de reconocimiento, identificación y toma de decisiones. Estos proyectos se basan en las Recomendaciones para la intervención en vías de paisaje y en sus principios de integración, funcionalidad y adaptación. También se proyectaron y presupuestaron actuaciones locales de menor importancia para dar respuesta a necesidades concretas de la red de caminos de cada concejo. Los proyectos-piloto y las actuaciones locales propuestas se adaptan a las necesidades de cada concejo, y se refieren a caminos de diferentes tipologías.

En el concejo de Ponga se optó por la mejora de un camino de uso agroganadero entre el núcleo de Ambingue y la majada de Viores. En un municipio de orografía agreste, donde habitualmente los mejores pastos para el ganado se encuentran alejados de los núcleos de población, en culminaciones montañosas de difícil acceso, la mejora del acceso a los pastos de Viores, muy utilizados por los ganaderos, se consideró preferente al dar respuesta directa a una necesidad de la población. También se proyectó la mejora de caminos de uso agroganadero que se encontraban en mal estado y comunican con buenas praderías en Santo Adriano y Yernes y Tameza, concejos en los que la mayor parte de la red caminera tiene uso agroganadero o de acceso, al no haber apenas explotación forestal en ellos. En el caso de éste último, a tales propuestas se sumó una actuación en el camino Fojó-Armada diseñada para dar realce al elevado valor paisajístico del entorno de la vía.

En Pesoz se propusieron dos actuaciones de mejora. Una de ellas, referida a un camino de uso forestal, puesto que en este concejo se explotan amplias matas de pino; 
y otra, sobre un camino recreativo, proponiendo la recuperación de un camino homologado de Pequeño Recorrido que se encontraba abandonado. En el otro concejo del occidente de Asturias, Santa Eulalia de Oscos, la actuación propuesta también se refirió a un camino de uso dominante recreativo, al tratarse de un municipio que recibe más turismo que los anteriores, si bien también tiene actividad agroganadera y de explotación maderera.

\subsubsection{PROPUESTAS DE SEÑALIZACIÓN, MANTENIMIENTO E INTERPRETACIÓN DEL CAMINO RURAL}

En cuanto a la fase del camino posterior a la obra, se elaboró en el marco de CRES un manual de señalización de caminos rurales, que puede tomarse como un esbozo para el desarrollo de sistemas de señalización normalizados. El equipo navarro, redactor de este manual, intentaba involucrar a las poblaciones locales a través de sistemas de señalización y difusión de las redes de caminos, partiendo de la hipótesis de que un adecuado tratamiento de la red de caminos rurales de determinado territorio, incluyendo una señalización normalizada y comprensible, así como la difusión de sus valores paisajísticos e históricos, puede contribuir a que recuperen su valor para la sociedad local, implicando a los usuarios tanto en el desarrollo de nuevas actividades económicas ligadas al camino (fundamentalmente recreativas) como en el de programas de mantenimiento.

El manual de señalización partió de una primera identificación de símbolos y colores a utilizar en los caminos rurales para elaborar diferentes tipologías de señales, desde señales de dirección hasta paneles de información general del camino. Se optó por elaborar una señalización simple y legible, de construcción económica y durable, para reducir gastos de instalación y mantenimiento.

A modo de complemento del sistema de señalización, y con el objetivo de contribuir a la valorización del camino y maximizar su potencial de uso recreativo, se realizó una ficha divulgativa que, a modo de colección, pueda ser ofrecida a los visitantes desde las oficinas de turismo y agencias de desarrollo local o descargarse de internet, ofreciendo, junto al sistema de señalización normalizado, una imagen asociada al camino rural fácilmente reconocible y comprensible para la población. La ficha de difusión recoge aspectos como el uso del camino, su historia, la presencia de elementos patrimoniales en su entorno y cartografía. 
Figura 12. Propuesta de señales normalizadas de dirección para la red de caminos rurales ${ }^{20}$.

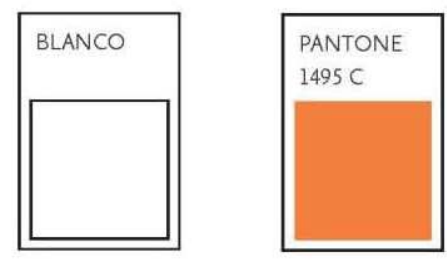

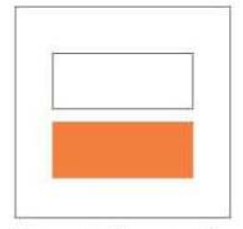

Dirección de recorrido

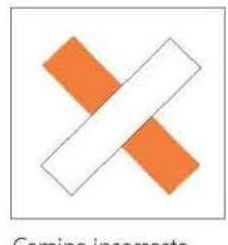

Camino incorrecto

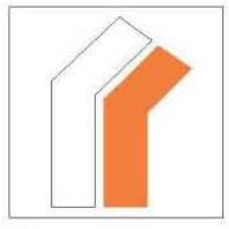

Giro

Fuente: Centro de Recursos Ambientales de Navarra.

Entendemos que la participación local es un instrumento importante para la buena conservación de las redes de caminos rurales, quizá exceptuando los de uso forestal, que dependen más de la actividad de empresas privadas. Para el mantenimiento de las vías, el equipo navarro de CRES organizó grupos de voluntariado ambiental que se ocupaban del desbrozado de los márgenes de los caminos y otros trabajos de mantenimiento. Tradicionalmente ha sido la población local la que se ha ocupado de tales tareas, y si bien hoy en día resulta indispensable dotar de financiación y estructura a este tipo de programas, el ensayo ha mostrado su potencial. Pero la adaptación de sistemas de mantenimiento por voluntariado a territorios montañosos de tipo rural profundo, con población escasa y envejecida y una red de caminos difícilmente manejable con pocos recursos humanos, como sucede muchas veces en Asturias, ofrece dificultades.

\footnotetext{
${ }^{20}$ Se utilizan los mismos símbolos que para la señalización de rutas de senderismo, empleando un color naranja que facilita la identificación como vía rural.
} 


\subsubsection{CONSOLIDACIÓN DE REDES DE TRABAJO}

Las aportaciones de CRES no se limitan a la prueba y propuesta de metodologías para todas las fases del camino. Si uno de los fundamentos de nuestra argumentación es la necesidad de que todos los agentes interesados tengan palabra en el proceso de toma de decisiones, entendemos que el esfuerzo realizado por el equipo asturiano del proyecto para establecer un contacto operativo entre ayuntamientos, administración autonómica, agentes de guardería, agentes de desarrollo local, población local, ganaderos, agricultores, empresas forestales, ingenierías y grupos de investigación, puede considerarse una aportación a tener en cuenta. Como primera aproximación a un campo complejo, donde operan voluntades e intereses muy diferentes, el esfuerzo ha ofrecido resultados desiguales. En algunos de los cinco municipios asturianos donde se probaron las metodologías CRES, el contacto resultó positivo y enriquecedor, dando lugar a consensos y mejorando la toma de decisiones de intervención. En otros lugares hubo menos comunicación, y las redes no funcionaron de la misma manera.

Entre Galicia, Navarra y Asturias se ha creado una red de trabajo en todo lo concerniente a los caminos rurales que tiene la ambición de ser nacional. Para su consolidación se celebraron seminarios abiertos organizados y gestionados por los socios de CRES. El primero de ellos, en Lalín (Pontevedra) a fines de febrero de $2010 \mathrm{y}$, el segundo, en mayo de 2011, en los municipios navarros de Araitz y Betelu, en la comarca de Norte de Aralar.

Queda como legado de CRES la constitución de redes de trabajo con experiencia y operativas. En Asturias, gracias a la movilización conseguida de todos los interesados, inspirada en la experiencia suiza, para la toma de decisiones de intervención y la obra. A escala nacional, mediante la constitución de una red de trabajo dedicada a los caminos rurales, cimiento sobre el que seguir trabajando y que tiene la necesidad de ampliarse, tanto por el interés que tendrían las aportaciones de grupos de investigación de otros territorios españoles, con otros y enriquecedores puntos de vista, como por la importancia de incluir, en futuras experiencias de parecida concepción, regiones y paisajes españolas que en CRES no tuvieron cabida, como el ámbito mesetario, el mediterráneo costero y muchos otros que contribuirían a consolidar el afán totalizador del proyecto original.

\section{CAMINOS QUE LLEVEN A UN LUGAR MEJOR}

Para Asturias la revisión de su Plan Forestal puede dar una oportunidad para introducir en él estas metodologías de consideración y actuación sobre una red rural caminera para hacerla más funcional, sostenible, segura y con capacidad de atender sosteniblemente a los diversos requerimientos capaces de lograr un medio rural dinámicamente ocupado. Para las tres regiones participantes en el proyecto ha resultado un mecanismo de conocimiento y reconocimiento y otra forma de hacer, ofreciendo ideas para la recuperación de grandes viales rurales y una metodología compartida para trabajar en el desarrollo del medio rural a partir de la movilidad que ofrecen los caminos. Hay una gran confusión tras el sintagma camino rural, preñado 
de sentidos y de competencias dependientes de múltiples actores de la administración y privados. Hay una gran fragmentación y abandono en la red caminera, que pierde capacidad a la vez que funcionalidad el medio cultural rural y con ello posibilidades de ser infraestructura. Este artículo ofrece un proyecto piloto, experimentado en todas sus fases, para el tratamiento integral de la red caminera rural.

\section{BIBLIOGRÁFIA}

DAL-RE, R. (2003). Caminos rurales. Ministerio de Medio ambiente y Medio rural y marino.

DAVIS, R. (2002). Forest Road Engineering Guidebook. Ministry of Forest British Columbia.

FERNÁNDEZ GARCÍA, F. (2002). Atlas Aéreo de Asturias. Los paisajes del S.XX. Prensa Asturiana.

GAYOSO, J y ACUÑA, M. (1999). Mejores prácticas de manejo forestal. Grupo de Producción Forestal y Medio Ambiente Universidad Austral de Chile.

IGLESIAS MERCHÁN C, ASENJO DÍAZ V, CASTELLANA RIBAS J. (2010). Estudios de paisaje: Ámbitos de estudio y aplicaciones prácticas. Madrid, Ecopás.

LLOP, C. (2009). Paisaje y transformación: integración y gestión paisajística. Diputación de Barcelona.

MATA, R y SANZ HERRAINZ, C (dir). (2003). Atlas de los Paisajes de España. Centro de publicaciones, Secretaría Técnica, Ministerio de Medio ambiente.

RODRÍGUEZ, F. (2009). Paisajes singulares de Asturias. Revista Ería, no 78-79, 125-138.

RUIZ, L (dir) (2005). Guidelines for road maintenance levels. US Department of Agriculture Forest Service.

SUÁREZ, S. (2005). Ecología del paisaje. Conceptos, método y aplicaciones. Instituto del Paisaje de Cataluña. 